\title{
Editorial: Introduction to Special Issue on Aging Families*
}

Population aging is a consequence of declining rates of fertility as well as improvements in mortality (Agree \& Hughes, 2012). These demographic trends are reconfiguring families in important respects. Having fewer children has decreased the size of families within generations, but longer life expectancies have increased the size of families across generations (Silverstein \& Giarrusso, 2010). In the past, the intergenerational composition of families resembled a pyramid - with large numbers of people in the younger generations and few in the older generations but families now resemble a beanpole, with fewer people in the younger generations and larger numbers in the older generations (Bengtson \& Silverstein, 1993). Since aging occurs within families, this structural change has implications for family relationships. What characterizes "beanpole" families is a decrease in the number of relatives to interact with, but it is also an increase in the duration of intergenerational relationships and an increase in the number of generations that co-exist.

The "verticalization" of families has occurred alongside other important demographic and social changes. Families have also been reconfigured through increases in divorce, remarriage, cohabitation, and step-families. These changes have implications for kinship structures and intergenerational relations in later life. In addition, the rise of women's labour market participation and the decline of traditional cultural and social norms have implications for the provision of support and living arrangements in later life. The state has been slow to respond to the realities of population aging, leaving it up to families to adapt. To address these issues, an international symposium on aging families was held in June 2013, sponsored by the Population Change and Lifecourse Strategic Knowledge Cluster, a Social Sciences and Humanities Research Council-sponsored knowledge dissemination initiative. The symposium included research from Canada, the United States, Europe, and China and covered a broad range of topics. The program included studies on living arrangements in later life, caregiving and caregiver burden, intergenerational exchange, and aging in poverty. This special issue of CJA/RCV presents nine articles from papers given at this symposium.

\section{Changes in Living Arrangements}

There has been a steady increase in the proportion of elderly people living alone or with only a spouse in the past three decades (United Nations, 2005). The most common preference is for aging-in-place or independent living in familiar environments (Cutchin, 2003). The trend in independent living is attributable to several factors, including rises in average income levels and the compression of morbidity. These factors have increased the economic opportunities for maintaining private households into old age and have postponed the medical/functional need for entering into co-residential or institutional dwellings. But there is wide variation in the living arrangements of older adults, and it is important to understand the social context and life course processes that determine these differences. This variation implies that opportunities for aging-in-place are not evenly distributed within the elderly population. Moreover, preferences for aging-in-place and other types of living arrangements are culturally determined (Kaida, Moyser, \& Park, 2009).

Lee and Edmonston provide a new perspective on the living arrangements of elderly immigrants. Prior research has tended to focus on the extended family living arrangements of elderly immigrants and has also neglected differences among them. Lee and Edmonston focus instead on the factors that are associated with differences in residential independence among immigrants. Their study uses recent census data to compare elderly immigrants and Canadian-born elderly individuals with respect to their living arrangements. Consistent with previous studies, the authors observe that residential independence is indeed less common among elderly immigrants than non-immigrants. But this difference is largely attributable to economic, life-course, and cultural attributes. What appears to account for much of the difference between immigrants and non-immigrants is a preference and/or need for co-residence among non-European immigrants. Lee and Edmonston's findings demonstrate the influence of cultural background and other contextual factors (e.g., age at immigration) on social differences in living arrangements in later life.

\footnotetext{
* The author gratefully acknowledges financial support from a Social Sciences and Humanities Research Council Strategic Knowledge Cluster grant and research assistance from Christoph M. Schimmele.
} 
The migration of the elderly population is tied to life-course factors such as retirement, widowhood, and onset of chronic health conditions (Litwak \& Longino, 1987). Edmonston and Lee's article offers an updated analysis of the trends and determinants of residential mobility of elderly Canadians. Using census data from 1971 to 2006, the authors observe that the residential mobility of older adults has changed substantially over time. About one in five elderly Canadians moved between 2001 and 2006, compared to one in three between 1966 and 1971. Since the oldestold are the least mobile and a growing population, Edmonston and Lee consider whether aging within the elderly population accounts for this temporal decline in mobility, but rule out this explanation. Two major late-life transitions - age at widowhood and onset of chronic conditions - have also declined, and thus a decreased need to move (aging in place) could explain both the increase in residential independence and the decline of residential mobility in later life.

\section{Context of Aging}

The next group of articles in this special issue assess how the context of aging influences well-being in later life and the provision and meaning of social support. What constitutes a family is an important question given social changes in nuptiality and fertility. The studies from the symposium demonstrate that there is considerable heterogeneity in aging families. This observation illustrates the limitation to defining families strictly according to legal or biological ties. This corresponds to a new agenda in gerontological research that calls for a more inclusive definition of families (Blieszner \& Hilkevitch Bedford, 2012). The studies in this special collection question our assumptions about aging families in several respects. First, it is shared experiences, not just legal or biological ties, that define kin group membership. Second, exchanges of social support are not just about reciprocity but are also about the creation of affective ties. Finally, the relationship between family status and well-being in later life is complex, and depends on factors such as gender, marital histories, and the outcome being considered.

McDaniel and Gazso provide insight into how the context of aging (e.g., low income and immigration) shapes familial relationships. Their article has important implications for how we define and measure family membership in later life. Their findings also improve our understanding of the meaning of social support in later life. McDaniel and Gazso observe that shared experiences within groups can re-define the traditional boundaries between kin and non-kin members. There are practical reasons for exchanges of social support, but these exchanges can also function to generate affective ties between non-blood relatives.
Close relations between non-kin members can, as McDaniel and Gazso state, forge "identities as members of a family by choice". The authors conclude that reciprocity is not always the primary motivation for intergenerational exchanges of social support: the motivation for such exchanges is also about maintaining the social relationships themselves. Giving and receiving social support is, therefore, about gaining a sense of belonging as well as tangible benefits.

Through their focus on 19 European countries, Clouston, Lawlor, and Verdery demonstrate that partnership status influences late-life physical function, after considering factors such as social network size, socioeconomic status, and health behaviours. In particular, the never married and the divorced fare worse on objective measures of physical function than do the married. For women, the authors found a non-significant difference between cohabitors and the married, but cohabitation does not appear to provide the same health benefits as marriage for men. The authors observe, however, that the effects of partnership status tend to be lower for women, which is consistent with the notion of a "his and hers" relationship between marriage and health (Kiecolt-Glaser \& Newton, 2001). Nonspousal relationships have the potential to replace some (but not all) of the benefits of a spousal partnership. Clouston et al. show that social engagement with friends and other relatives can "buffer" the relationship between partnership status and health.

Penning and Wu's article examines how marital status and childlessness influence unpaid social support from outside the household in later life. Their research contributes to theoretical debates about the importance of marital and parental statuses for social support in later life. Their findings demonstrate that there is not a straightforward link between these statuses and the receipt of social support. In contrast to theories that suggest that married people with children should have better access to support than others, Penning and $\mathrm{Wu}$ observe that there is not a clear advantage to being married nor is there a clear disadvantage to being unmarried and/or childless. The authors find limited support for notions of the "primacy of the nuclear family for the provision of support". There is considerable heterogeneity in the receipt of support in later life, Penning and Wu conclude, and the likelihood of receiving support is complex, and depends on marital histories, the presence of children, and the type of support.

\section{Caregiving and Caregiver Burden}

In most societies, families provide the bulk of caregiving to aged parents (Pruchno \& Gitlin, 2012). With increased life expectancies and limited public services, 
the number of informal caregivers has increased, and the length of time people spend as caregivers is increasing. This special issue includes several articles that examine the determinants of caregiving, the formation of care networks, and the influence of caregiving on stress and role strain. To be sure, these studies demonstrate the challenges associated with caregiving but show the positive side of caregiving as well. In most cases, caregivers appear to fare well, and caregiving is more ample and perceived as less burdensome when it corresponds to a sense of obligation or a long-term commitment between the caregiver and care recipient. The two areas of concern that emerged from these studies were the gendered nature of caregiving and socioeconomic barriers to access to care in later life.

Zuo, Li, Mao, and Chi examine a rural area in China to address end-of-life caregiving. This is an important topic considering that the need for care peaks at this life stage. In China, formal care services are sparse in rural areas, and there are strong expectations (filial piety) for children to support their parents in later life. Consistent with cultural norms, Zuo et al. observe that the eldest sons and daughters-in-law provide more care than daughters (and their husbands) and younger sons. However, the authors remark that this gendered pattern of care is weakening in the context of economic change and rural-to-urban migration. In China, the provision of care also reflects a reciprocal relationship. This article demonstrates that prior intergenerational exchanges of support increase the amount of care children provide to their parents at the end-of-life stage. This finding suggests that the optimal social support networks are those that are built up and maintained over the long term.

Much of the literature on caregiving burden does not distinguish between spouse and adult child caregivers. Chappell, Dujela, and Smith demonstrate that the relationship between the caregiver and care recipient matters. Using longitudinal data, the authors compare the burden of caring for a spouse versus caring for a parent with dementia. Most caregivers are not overburdened, according to Chappell et al., but the authors observe that adult children experience more burden than spouses. Their research illustrates the contextual factors that contribute to this difference. The relationship between caregiver and care recipient matters for at least two reasons. First, it could influence how caregiving is perceived. A spouse could view caring for their partner as part of their marital vows, while an adult child could view it more as an obligation that increases their workload. Second, both groups are at different life-course stages, with adult children having other responsibilities to fulfil. The competing demands of multiple roles could also add to their experience of caregiver burden.
Rutherford and Bowes argue that caring is best understood using a network approach, and that a multidisciplinary perspective is needed to understand the complexities of caring relationships in older age. The authors demonstrate that most care networks have a strong core - usually the spouse or an adult child which is supplemented by a secondary layer of support. These care networks are rarely planned in advance of old age. Rutherford and Bowes observe that the formation of these networks often depends on the decisions of others or the resources available to caregivers and care recipients. There appears to be reluctance among older people to ask for help or to anticipate asking for help when needed, which could explain their lack of planning for care. Advance planning leads to better outcomes, but the capability of making plans for care is associated with financial well-being. Thus, disadvantages in personal resources can lead to cumulative disadvantage in later life since it represents a barrier to care planning.

Proulx and Le Bourdais assess the impact of caregiving on the risk of leaving employment. The authors demonstrate that women who are employed fulltime are the most vulnerable to leaving employment when caring for a parent. This suggests that fulltime employment is either too demanding or inflexible to accommodate caregiving. In contrast, women who are employed part-time and are caregivers have a lower risk than their non-caregiving counterparts. Proulx and Le Bourdais suggest that, when not too demanding, part-time work could provide women a welcome break from caregiving. Being sandwiched between caring for parents and children also influences work interruptions. Although holding multiple roles can lead to additional demands, the satisfaction of employment (or need for income) can be a disincentive to leaving work. While the authors find few gender differences in the impact of caregiving on leaving employment, this likely reflects the greater proportion of women in part-time work, which provides them enough flexibility to combine work and caregiving.

\section{Concluding Remarks}

Two core themes emerge from these studies. First, there is the theme of diversity. With changes in family structure and the ethno-racial composition of societies, aging families have become more heterogeneous, and these differences have implications for family relations and personal preferences in later life. The key aspects of diversity in aging families include differences in gender roles across the life course and differentiation within the older population (Bengtson \& Silverstein, 1993). Current cohorts are entering old age with different capacities and expectations because 
of differences in marital histories, socioeconomic status, and cultural backgrounds. This turns our attention to the second core theme: complexity. With growing diversity, the context of aging and relationships in later life are becoming more complex. This complexity is reflected in social differences in preferences of living arrangements, the meaning of social support, the effects of marital status, and the provision and impact of caring.

Zheng Wu

Guest Editor

\section{References}

Agree, E.M., \& Hughes, M.E. (2012). Demographic trends and later life families in the 21st century. In R. Blieszner \& V. Hilkevitch Bedford (Eds.), Handbook of families and aging (pp. 9-34). Santa Barbara, CA: Praeger.

Bengtson, V.L., \& Silverstein, M. (1993). Families, aging, and social change: Seven agendas for 21st-century researchers. Annual Review of Gerontology and Geriatrics, $13,15-38$.

Blieszner, R., \& Hilkevitch Bedford, V. (Eds.) (2012). Handbook of aging families. Santa Barbara, CA: Praeger.
Cutchin, M.P. (2003). The process of mediated aging-in-place: A theoretically and empirically based model. Social Science and Medicine, 57(6), 1077-1090.

Kaida, L., Moyser, M., \& Park, S.Y. (2009). Cultural preferences and economic constraints: The living arrangements of elderly Canadians. Canadian Journal on Aging, 28(4), 303-313.

Kiecolt-Glaser, K., \& Newton, T. (2001). Marriage and health: His and hers. Psychological Bulletin, 127(4), 472-503.

Litwak, E., \& Longino, C.F. (1987). Migration among the elderly: A developmental approach. The Gerontologist, 27(3), 266-272.

Pruchno, R., \& Gitlin, L.N. (2012). Family caregiving in later life: Shifting paradigms. In R. Blieszner \& V. Hilkevitch Bedford (Eds.), Handbook of families and aging (pp. 515-541). Santa Barbara, CA: Praeger.

Silverstein, M., \& Giarrusso, R. (2010). Aging and family life: A decade review. Journal of Marriage and Family, 72(5), 1039-1058.

United Nations. (2005). Living arrangements of older persons around the world. New York, NY: Department of Economic and Social Affairs, Population Division, United Nations. 